\title{
O bibliotecário escolar incentivando a leitura através da webquest
}

Wilse Arena da Costa

\author{
Profa. Dra. do Curso de Pedagogia da UFM \\ Campus de Rondonópolis, MT - Brasil
}

Mariza Inês da Silva Pinheiro

Professora efetiva do Curso de Biblioteconomia da Universidade Federal de Mato Grosso. Doutoranda do curso de Biblioteconomia da UFMT.

Maria Neuma da Silva Costa

Bacharel em Biblioteconomia na UFMT

Rondonópolis, MT - Brasil

O estudo teve por objetivo averiguar o uso da Webquest para incentivar o gosto das crianças pela leitura, e foi realizado junto à $5^{a}$ série de uma escola pública do Ensino Fundamental. A metodologia adotada consistiu na pesquisa-ação, em que foi elaborada e aplicada uma Webquest com um grupo de dez alunos. Ao analisar a Webquest desde a sua construção e aplicação até a obtenção dos resultados, procurou-se verificar se este instrumento, que utiliza basicamente recursos da Internet, apresenta algum benefício ao desenvolvimento do gosto pela leitura. Foi diagnosticada, através da observação participante, a eficiência do uso da Webquest desenvolvida pelas pesquisadoras e explorada pelos alunos em atividades de leitura.

Palavras-chave: Bibliotecário escolar; Internet na educação; Incentivo à leitura; Metodologia Webquest.

\section{The school librarian encouraging reading through webquest}

The study aimed at verifying the use of the Webquest in order to develop the reading interest of children in the $5^{\text {th }}$ grade of a Public Elementary School. The adopted methodology was the research-action, and an Webquest which basically uses resources from the Internet - was 
elaborated and applied to a group of ten students. Through the analysis of the Webquest, from its elaboration and application until reaching the results, we tried to verify whether it had any kind of benefit in terms of developing the interest in reading. Through a participative observation, it could be noticed that the use of the Webquest developed by the researchers and explored by the students in reading activities was very effective.

Keywords: School librarian; Internet in the education; Reading Encouraging; Webquest Methodology

Recebido em 21.11.2008 Aceito em 12.03.2009

\section{Introdução}

É oportuno lembrar que vivemos na chamada sociedade da informação, na qual a velocidade do desenvolvimento das tecnologias da informação tem afetado diversos campos do conhecimento e, em particular, a educação, causando mudanças contínuas. Dessa forma, os profissionais da educação, inclusive o bibliotecário escolar, confrontam-se com novas perspectivas de ensino geradas pelo fenômeno da Internet, que constitui um novo recurso didático-pedagógico a ser utilizado no processo de ensino e aprendizagem da leitura e da escrita, principalmente porque os educandos já não se contentam mais com os tradicionais métodos pedagógicos utilizados nas práticas escolares.

Neste contexto, cabe ao bibliotecário intervir no processo de ensinoaprendizagem da leitura e desenvolver atividades que estimulem e motivem a busca do conhecimento, em especial o gosto pela leitura, e que estimulem também o corpo docente e o corpo discente a se beneficiarem das possibilidades oferecidas pela tecnologia disponível. Esse profissional assume, deste modo, papel importante como co-responsável pela superação de dificuldades apresentadas por inúmeros leitores que, embora tenham aprendido a decodificar os códigos lingüísticos, não conseguem interpretar o que lêem, nem estabelecer relações com o cotidiano, reproduzir o texto com suas próprias palavras, entre outros problemas, principalmente quando se trata de um texto mais complexo. Acerca desta questão, Minini (2004, p. 2), referindo-se aos resultados do Programa Internacional de Avaliação de Alunos (PISA), enfatiza que "[...] - brasileiro decifra letras, lê frases, mas não compreende seus significados, o que se deve principalmente ao baixo índice de leitura".

Perante essa realidade, considerou-se importante a aplicação da metodologia Webquest na Escola Carlos Pereira Barbosa, como um meio de despertar o gosto pela leitura nos educandos e de contribuir no processo de aprendizagem dos professores quanto à utilização de 
metodologias diferenciadas para o ensino da leitura e da escrita em sala de aula.

A metodologia Webquest é uma atividade de aprendizagem instigante, pois permite ao aluno adquirir conhecimento através da pesquisa pela Internet, como também utilizando outros meios informacionais. De acordo com Dodge (1995, p.4), "as WebQuests têm a virtude da simplicidade. Podem ser desenvolvidas para alunos da escola elementar à pós-graduação". É o uso da tecnologia, em especial do computador, da Internet, para a implantação de novas formas de disseminação da informação em prol do conhecimento.

Acredita-se que com esse recurso ampliam-se as possibilidades, tanto do bibliotecário escolar quanto do professor, para incentivar o aluno a ler mais, principalmente aquele que não gosta das atividades de leitura tradicionais. A leitura, por meio da Metodologia Webquest, permite ao aluno a realização orientada de pesquisas, o que impede que ele se perca no universo da grande rede. Afinal, deve-se ter em mente que a leitura é o eixo de todo o processo ensino-aprendizagem.

\section{A informática na escola}

A informática tem se tornado cada vez mais indispensável na vida do indivíduo. Segundo Marques Neto (2006, p.52), além de "influenciar algumas atividades elementares do cotidiano do sujeito contemporâneo, a informática também interfere na forma como ele lida com a informação necessária à sobrevivência". Já não há mais como esquivar-se desta realidade tecnológica, e a educação não pode ficar para trás, pois tais mudanças influem também na aprendizagem ou nos modos de se aprender, já que a informação necessária ao aprendizado passa por meio dos recursos dessa tecnologia. Ainda de acordo com Marques Neto (2006), deve-se considerar que o sujeito contemporâneo passa grande parte de sua existência dentro de uma unidade escolar. Deste modo, a escola precisa se manifestar, não deixando de fora os seus educandos. Cabe a ela fornecer os meios necessários à busca de conhecimentos para a construção do saber, que tem influência direta nas relações sociais e profissionais que os seres humanos estabelecem com 0 meio na contemporaneidade.

Sobre a utilização da informática no processo de ensino e aprendizagem, pode-se afirmar que o computador constitui um dos elementos tecnológicos geradores de mudanças capazes de promover e difundir novas idéias dentro da educação, visando à melhoria desta. Conforme explica Valente (200-?, p.1), "[...] informática na Educação significa a inserção do computador no processo de aprendizagem dos conteúdos curriculares de todos os níveis e modalidades de educação[...]". Todavia, este autor considera pouco provável que o professor seja capaz de inserir adequadamente atividades tradicionais de ensino-aprendizagem e/ou construir conhecimento através do uso do computador se não for capacitado para isso. 
Também se deve observar que o fato de a escola equipar-se com computadores não garante que este recurso seja capaz de contribuir de forma significativa para o processo de construção do conhecimento. A informática, quando introduzida nas unidades escolares, precisa se agregar ao espaço e à realidade dos alunos, não apenas como uma ferramenta, mas como um recurso para as atividades curriculares. Nesta perspectiva, Corrêa (2006, p.47) alerta que "as tecnologias que favorecem o acesso à informação e aos canais de comunicação não são, por si mesmas, educativas [...]". Antes, porém, complementa a referida autora, é preciso que os professores considerem a informática na educação como sendo apenas um apoio pedagógico e não uma metodologia de ensino; que eles percebam que o correto emprego da informática só irá facilitar o seu papel de educador capaz de propiciar a construção do conhecimento.

Isto significa que os profissionais da educação precisam redirecionar sua formação pedagógica, não apenas aprendendo a utilizar novas ferramentas, mas também, e sobretudo, mudando suas atitudes e posturas diante do mundo, do conhecimento e do processo de ensino: estando aberto às mudanças, readaptando o seu saber à nova realidade, enfrentado desafios, atendendo à diversidade que o novo cenário educacional exige deles.

Destacando a importância da formação docente nesta área, Valente aponta que "[...] o processo de formação deve oferecer condições para o professor construir conhecimento sobre as técnicas computacionais e entender por que e como integrar o computador na sua prática pedagógica". Também para Seabra (1994, p.2) o "papel dos educadores deve ser repensado e novas estratégias na formação desses profissionais devem ser previstas [...] a escola está imobilizada na antiquada formação de 'erudição' [...]". Este mesmo autor lembra que a escola precisa também cumprir seu papel de educar o aluno para esse novo cenário. Assim sendo, a qualificação do professor e a compreensão do porquê e de como integrar o computador na sua prática pedagógica, bem como o repensar sobre suas atitudes como docente, são fundamentais para sua prática, pois permitem o acompanhamento do ritmo da evolução tecnológica e a compreensão de que o computador pode ser uma ferramenta determinante na busca de mudanças no processo educativo.

Por outro lado, Seabra (1994) lamenta o modo como o computador tem sido utilizado nas escolas: na maioria das vezes para o ensino da informática. Acrescenta que apenas uma minoria direciona o uso do computador para a prática da educação.

\subsection{Algumas alternativas no incentivo da leitura}

É fato conhecido que, em tempos remotos, era empregado o uso de desenhos rupestres para a comunicação. Fragoso e Duarte (2004) afirmam que o homem sempre teve a preocupação de preservar seu conhecimento e que, ao longo do tempo, diversos suportes foram utilizados com a finalidade de armazenar as idéias, desde a pedra, o 
pergaminho, o papel, até o computador. Mencionam ainda que, devido a essas mudanças de suportes da escrita, facilitou-se cada vez mais a forma da leitura, ampliando-se, assim, o acesso ao conhecimento.

Neste mesmo sentido, Zilberman (1988, p.14) comenta que...

[...] com a invenção da imprensa no século XV, a leitura tornou-se uma atividade extremamente importante para 0 homem civilizado, com múltiplas finalidades, influenciando o desenvolvimento da sociedade contemporânea e tornando-se uma das grandes responsáveis pelas mudanças ocorridas na evolução da humanidade.

Assim sendo, necessário se faz adotar a prática da leitura desde bem cedo, criar estratégias que contribuam para que o jovem possa perceber que a leitura é capaz de modificar o meio e que, portanto, saber ler é uma condição indispensável para a participação ativa na sociedade.

Acerca deste tópico, Silva (1995, p. 49) salienta que ler "é possuir elemento de combate à alienação e ignorância [...] o ato de ler se constitui num instrumento de luta contra a dominação". O processo da leitura, como se pode ver, é notoriamente vital ao indivíduo e, também, de extrema importância para o desenvolvimento escolar. Entretanto, esta não é uma prática fácil de se exercitar; a educação intelectual exige prática contínua, de preferência ainda no colo maternal. Hillesheim e Fachin (2003) alertam que a prática da leitura deve ser instigada ainda em idade pueril, em um primeiro momento no ambiente familiar e posteriormente nos primeiros anos da vida escolar. A criança que tiver adquirido o gosto pelo livro desde a infância desenvolverá o gosto pela leitura, tornado-se, quando adulto, um leitor assíduo, com mais criatividade, autoconfiança, senso crítico e facilidade de captar a dinâmica do mundo que a cerca.

Costa (2006, p. 72) sugere exercícios de trabalho com as crianças para o crescimento intelectual. Nesta visão, ouvir e contar histórias é a melhor maneira de "contribuir para o desenvolvimento de habilidades e competências, tais como: atenção, concentração, observação, memória, análise e síntese".

Acerca desta atividade, ressalta-se com Kuhlthau (2002, p.50) que "[...] as crianças devem escutar histórias, a fim de desenvolver 0 interesse pelos livros e conscientizar-se da variedade de livros disponíveis. Quando estão aprendendo a ler, a escuta de histórias funciona como uma influência modeladora para a leitura".

Assim sendo, entende-se que a hora do conto, além de ser uma das principais atividades da biblioteca escolar para promover a motivação e despertar a curiosidade e o interesse das crianças pela leitura, também pode ser um valioso recurso pedagógico-cultural, uma vez que elas vivenciam o encantamento dos sentimentos contraídos através da leitura, 
- que as ajuda a criar uma afinidade maior com o livro, propiciando momentos agradáveis de contato com o mundo mágico da literatura oral.

Todavia, é preciso também que se fique atento para outros meios de propagação da leitura, originados pelas novas tecnologias, que, da mesma forma, devem ser trabalhados pela educação. Lévy (1999 apud BELMIRO, 2006, p.20) aponta para essa questão quando menciona que "o excluído é o que se encontra desconectado, não participa da densidade relacional e cognitiva das comunidades virtuais e da inteligência coletiva". Por isso, as instituições de ensino não podem mais omitir-se diante deste novo modo de ler ocasionado pela informática, em especial do uso da Internet como um meio inovador de se estimular a leitura.

Também Moran (1997, p. 2) lembra que a Internet "[...] está explodindo na educação. Universidades e escolas correm para tornar-se visíveis, para não ficar para trás. Uns colocam páginas padronizadas, previsíveis, em que mostram a sua filosofia, as atividades administrativas e pedagógicas".

Diante das constatações dos autores supracitados, comprova-se a importância da criação de técnicas inovadoras que apresentem a aprendizagem de modo diferenciado, ou seja, a utilização de diferentes métodos. Já não há mais como negar as mudanças no cenário da leitura e as responsabilidades da escola geradas pelas novas tecnologias.

\section{Biblioteca escolar}

A biblioteca da escola tem a função de educar. É um centro ativo de aprendizagem imprescindível no processo educacional e no desenvolvimento de aptidões de leitura e escrita, no uso da informação, no ensino e aprendizagem. De acordo com a IFLA/UNESCO (2000, p.4), a "[...] biblioteca escolar desenvolve nos estudantes competências para a aprendizagem ao longo da vida e estimula a imaginação, permitindo-Ihes tornarem-se cidadãos responsáveis". Por isso é de fundamental importância o cumprimento correto da sua missão e de seus objetivos.

A missão da biblioteca escolar, também segundo a IFLA/UNESCO (2000), está direcionada a todos os membros da comunidade escolar. Nesse sentido, oferece serviços de apoio à aprendizagem (como livros e outros recursos que viabilizem a informação), e idéias fundamentais para o desenvolvimento bem sucedido dessa comunidade, propiciando a seus integrantes que se tornem pensadores críticos e permanentes usuários da informação (em todos os formatos e meios), e auxiliando os educandos no processo de aprendizado, no desenvolvimento da reflexão e no enriquecimento de seu vocabulário. Cumprir seus objetivos e suas funções, desenvolver políticas e serviços, selecionar e adquirir recursos, prover acesso físico e intelectual e adequadas fontes de informação, fornecer ferramentas e equipamentos educativos e se envolver no treinamento de pessoal fazem parte da sua missão.

Para Costa e Hillesheim (2004), é no ambiente da biblioteca escolar que crianças e jovens complementam sua aprendizagem e desenvolvem criatividade, imaginação e senso crítico, reconhecendo a complexidade do 
mundo que os rodeia e adquirindo novos conhecimentos. Antunes (1993, p. 69) considera que "[...] as atividades culturais e recreativas devem ser previstas. Além de aumentarem a bagagem de informação dos alunos, elas servem para atrair à biblioteca os usuários potenciais, que, ao serem estimulados, espera-se que passem a freqüentá-la com regularidade".

Contudo, para cumprir bem sua missão a biblioteca precisa estar totalmente integrada à prática desenvolvida na escola. No Manifesto IFLA/UNESCO (2000), consta que os bibliotecários e professores, ao trabalharem em conjunto, influenciam o desempenho dos estudantes. Percebe-se, assim, a necessidade de haver uma cooperação entre esses profissionais, para uma melhor qualidade dos serviços prestados, em beneficio do próprio educando. Porém, não se deve esquecer que, para que se atinja essa qualidade, outros elementos se tornam imprescindíveis, como uma infra-estrutura adequada, um acervo compatível com as necessidades dos usuários, um espaço apropriado e um pessoal capacitado.

Vê-se em Corrêa et al. (2002, p.102) que "[...] a realidade das bibliotecas escolares brasileiras (especialmente no que se refere às escolas da rede pública de ensino) apresenta um quadro diferente daquele que a teoria pretende demonstrar[...]". Aliás, já na década de 90, Silva (1995), em seu livro Miséria da biblioteca escolar, retratou muito bem o caos em que se encontra a maioria das bibliotecas do país. Segundo essa autora (1995, p.11), "[...] a biblioteca escolar brasileira encontra-se sob o mais profundo silêncio: silenciam as autoridades, ignoram-na os pesquisadores, calam-se os professores, omitem-se os bibliotecários".

Com base nas reflexões apresentadas acima, percebe-se que ainda hoje as bibliotecas escolares brasileiras apresentam inúmeras deficiências em seu funcionamento, de modo geral. Contudo, evidencia-se também que a biblioteca escolar não pode mais ficar isolada, ela deve participar, priorizando a satisfação e a capacitação da comunidade escolar.

Neste contexto, de acordo com Martucci (1999, p.34),

[...] volta-se a falar em biblioteca escolar de uma maneira renovada frente às novas demandas da educação e estas considerações mundiais já estão representadas no país pelas políticas públicas na área de educação. Pode-se exemplificar esta assertiva pelos Parâmetros Curriculares Nacionais - PCN, que propõem orientações gerais sobre o básico a ser ensinado e aprendido nas oito séries do ensino fundamental, especialmente o de Língua Portuguesa, que está apoiado na existência de uma biblioteca escolar para o desenvolvimento da leitura.

Hoje em dia o bibliotecário pode atuar em bibliotecas (virtual, digital, especializada, pública, universitária ou escolar), museus, editoras, centros de documentação, TV, centros culturais, arquivos, centros de memória, rádio, empresas privadas e organizações de bases de dados virtuais, cartórios, fóruns, discotecas, agências de publicidade, entre 
outros lugares e espaços. Ele também pode atuar como consultor de serviços de informação em geral, além de atuar na área docente do ensino superior. Deste modo, pode-se observar que o profissional bibliotecário, na atualidade, tem como principal objetivo promover 0 acesso à informação e auxiliar o usuário na busca e utilização da mesma.

Porém, para que alcance o êxito no desenvolvimento de suas atividades, ele deve levar em consideração algumas características do usuário final. No caso da biblioteca escolar, o bibliotecário precisa estar ciente do seu papel de educador. Hillesheim e Fachin salientam que...

[...] cabe ao bibliotecário e somente a ele a função de priorizar entre as tarefas do processamento técnico e as de atendimento à comunidade escolar para buscar a satisfação dos usuários; cabe a ele demonstrar a importância de seu trabalho como educador, como incentivador da leitura, representando 0 real significado da biblioteca escolar (HILLESHEIM; FACHIN, 2003, p. 38).

O bibliotecário deve promover atividades que desenvolvam os conhecimentos de seus usuários, procurando incluí-los em atividades culturais. Diferentes recursos podem ser empregados (hora do conto, dramatizações, teatro de fantoches, palestras e outros). É preciso fazer da biblioteca um espaço atrativo para alunos e professores. Ainda de acordo com Hillesheim e Fachin (2003), compete ao bibliotecário promover também a sua própria inclusão na comunidade escolar, participando de reuniões pedagógicas, do planejamento anual e de todas as atividades da sua instituição educacional, interagindo, estando e se fazendo presente na escola. Também Kuhlthau (2002) ressalta a importância de se integrar a programação da biblioteca escolar com as atividades desenvolvidas na sala de aula, e afirma ser necessário o envolvimento de professores com bibliotecários, no sentido de assegurar 0 adequado andamento do processo de ensino-aprendizagem. Com essas observações, percebe-se que o profissional bibliotecário atuante pode e deve desencadear um processo de valorização profissional, sendo um agente ativo dentro do processo educacional. Para que isto ocorra na biblioteca onde trabalha, ele deve desempenhar todas as suas funções, sendo uma ferramenta catalisadora no processo de aprendizagem, pois do contrário a presteza bibliotecária passa a ser questionada. Entretanto, é necessário que o bibliotecário se conscientize da sua função de educador e, principalmente, seja capaz de convencer o corpo docente da escola dessa sua função, sendo criativo, dinâmico e participativo dentro e fora do ambiente da biblioteca, mostrando toda a sua capacidade, tendo um bom desempenho de mediador da informação.

A esse respeito, Blattmann e Cipriano (1998, p. 8) enfatizam que "o bibliotecário precisa agir para favorecer práticas de leitura de diferentes fontes de informação, propiciar espaços de leitura e minimizar a exclusão social. Lembrando a importância da aculturação digital para todos". É fato que os computadores estão sendo incorporados a todos os setores da sociedade em geral, de modo cada vez mais rápido, surgindo, assim, a 
necessidade de se adaptar à realidade imposta. Dodge (1995) defende que novas estratégias possam ser imaginadas para a aplicação da Webquest a outras atividades, tais como à educação a distância e ao ambiente de bibliotecas. Desta forma, a Webquest como um recurso pedagógico pode ser de grande serventia no incentivo à leitura.

\section{Webquest}

O conceito de Webquest foi criado em 1995, por Bernie Dodge, professor de Tecnologia Educacional da Universidade de São Diego (Califórnia). No site Educarede (2001) há a informação de que, segundo Carlos Seabra, coordenador do projeto Webquest da Escola do Futuro da Universidade de São Paulo (USP), a "grande vantagem do WebQuest é dar um outro enfoque à questão da pesquisa na Internet. Os alunos entram na rede buscando temas definidos, com tarefas específicas". Vê-se, pois, que a Webquest tem mostrado ser, efetivamente, uma metodologia de pesquisa que aproveita adequadamente as informações encontradas na web. Dodge (1995) afirma que um dos principais benefícios da Webquest é o de orientar o discente no uso criativo da Internet, sem interferir nos rumos da pesquisa.

Conforme Moran (2007, p.4), em geral, "uma Webquest é elaborada pelo professor, para ser solucionada pelos alunos". Apresenta um tema que indica uma tarefa a ser realizada, que deve ser solucionada através de consulta a fontes de informação provenientes de qualquer meio informacional; porém, na maioria das vezes, as fontes são sites da Internet especificamente selecionados pelo professor.

De acordo com o SENAC (2003), o planejamento de uma Webquest integra alguns elementos básicos essenciais à sua formação estrutural, tais como:

a) Introdução: Aqui se apresentam o tema e as atividades que deverão ser realizadas. Nesta fase, é dada alguma informação preliminar que deve fornecer dados básicos para despertar o interesse dos alunos pela tarefa por meio de um texto curto, direto, instigante e motivador;

b) Tarefa: É a parte principal de uma Webquest, por isso tem que ser clara e executável. Deve determinar algo a ser realizado pelos alunos que seja plausível de ser desvendado e também capaz de entusiasmar os estudantes, dando espaço para muita criatividade. Sintetizando, a tarefa é o objetivo do trabalho;

c) Processo: Indica o caminho que o aluno terá de percorrer para realizar a pesquisa. Deve indicar todos os passos de cada etapa. Aqui também é preciso definir os grupos, se houver, o número de integrantes, o papel de cada um no desenvolvimento das atividades que vêm a seguir e os recursos a consultar. Deve indicar a direção do desenvolvimento da tarefa, sem, no entanto, esquecer que a autonomia e a criatividade na escolha da informação selecionada pertencem ao estudante. Em síntese, o processo é a metodologia; 
d) Recursos: São preferencialmente fontes disponíveis na Internet, entretanto outras fontes, como informações obtidas em bibliotecas, podem ser incluídas. Somente não se pode esquecer a importância da qualidade e da quantidade de informações oferecidas no recurso: quanto mais disponibilidades melhor;

e) Avaliação: Informa sobre como o desempenho do estudante será avaliado e se esta avaliação será individual ou em grupos. Os métodos da mesma devem ser concretos e rigorosos, de modo que cada aluno compreenda bem como vai ser avaliado o seu trabalho. Recomenda-se o uso da rubrica;

f) Conclusão: Esta deve dar ênfase a tudo que os alunos aprenderam com a investigação e despertar a curiosidade para pesquisas futuras, proporcionando, assim, mais sentido à aprendizagem;

g) Créditos: A seção de Créditos é o espaço no qual são apresentadas as fontes utilizadas e os agradecimentos a colaboradores da elaboração da Webquest.

Dodge (1995) classifica a Webquest como sendo de curta ou longa duração, o que implica considerar o grau de aprendizagem que se quer atingir. A seleção do conteúdo, além de estar vinculada às exigências curriculares, deve considerar a faixa etária dos alunos, podendo ser definida como de curto prazo (de um dia até uma semana), que abrange a aquisição e integração do conhecimento, ou de longo prazo (de uma semana até um mês ou mais), quando a finalidade é alargar e refinar o conhecimento. A aplicação desse instrumento tecnológico nas atividades escolares poderá motivar e aguçar a curiosidade dos alunos, tornando-os produtivos e construtores do próprio conhecimento.

No site do SENAC (2003) vê-se que, além de ser uma ferramenta de fácil utilização, a Webquest não exige softwares específicos, além dos utilizados comumente para navegar na rede e produzir páginas, textos e imagens. Ela requer apenas algumas noções de informática, as mesmas empregadas normalmente ao se navegar na Internet.

Em contrapartida, Rhatto (2006) previne que, se não se souber o fundamental sobre HTML, é praticamente impossível que se possa criar e publicar uma página na Internet. O despreparo de alguns professores em relação ao manejo das tecnologias da informação e comunicação é uma realidade preocupante, sobretudo diante da responsabilidade das instituições públicas de ensino em inserir o computador no cotidiano do educando.

Pensando exatamente nessas dificuldades, Barros (2005, p.8) informa que pesquisadores da equipe do Portal EscolaBR criaram um site para se pesquisar e divulgar, através de projetos educativos, ferramentas on-line para utilização gratuita de educadores de escolas públicas de todo o Brasil.

Esses mesmos iniciaram, no final de 2001, uma investigação sobre um meio que pudesse facilitar a elaboração da Webquest. Diante de diversos softwares pesquisados e analisados, em julho de 2005, eles encontraram um programa educativo desenvolvido pelo professor 
espanhol Antonio Temprano: o software livre PHPWebquest. Este possuía um layout semelhante às sessões do gabarito sugerido por Dodge (1995) para a elaboração de uma Webquest. O professor Eziquiel Menta traduziu para o português o software livre PHPWebquest, que, com algumas pequenas adaptações, foi disponibilizado a educadores de todo o Brasil para a criação de Webquest, sem que para isto fosse necessário escrever em código html ou utilizar programas de edição de páginas na web. Os educadores interessados em usar o PHPWebquest podem solicitar uma conta, que é autorizada no site http://livre.escolabr.com/ferramentas/wq/. Os usuários recebem uma senha através de e-mail, que Ihes dá acesso direto à sua Webquest. Podem criar e editar, atualizar ou apagar as suas atividades quando quiserem, bastando apenas que estejam conectados à Internet. Suas produções têm hospedagem gratuita no EscolaBR, desde que sejam para fins educativos.

\subsection{A Webquest como ferramenta educacional}

Tem-se verificado que a pesquisa é uma prática comum nas instituições educacionais, do Ensino Fundamental à educação superior, caracterizando-se como um modo de busca de informação e de conhecimento. De acordo com Hillebrand (2003) e Kuhlthau (1999), a pesquisa é uma importante ferramenta na construção do conhecimento, pela qual o indivíduo pode ser capaz de raciocinar por si e posicionar-se perante as informações que chegam até ele. Estes autores concordam que os questionamentos adquiridos através da pesquisa fazem com que o aluno se torne um sujeito ativo, com desenvoltura para construir novas informações e articulá-las com conhecimentos anteriormente adquiridos.

Para Hillesheim e Fachin (2003, p.2), a "[...] escola não pode mais apresentar uns saberes estáticos, uniformes e únicos, mas saberes dinâmicos, múltiplos, variados e procedentes de muitas fontes". Neste contexto, a pesquisa torna-se um recurso propício para o bom desempenho da aprendizagem; e novas ferramentas podem ser adicionadas para que 0 ato de pesquisar seja aprimorado, como a Internet, por exemplo, que é um excelente recurso para se empregar na pesquisa dentro do ensino, pois possibilita o acesso a um rico repositório de informações. Neste sentido, Moro, Sabbadini e Estabel (2002, p. 8) salientam que a "presença das tecnologias no dia-a-dia da escola, propiciando a integração da Internet aos sistemas educacionais, torna-se mais um recurso e mais uma fonte de informação na promoção do ensino e da aprendizagem [...]". Percebe-se claramente a eficácia do uso da Internet como um instrumento facilitador no processo educativo da busca da informação: além de promover a aquisição de conhecimento, contribui para o acesso a variadas fontes de informações atualizadas.

Também Santos $(2003$, p.3) observa que "[...] a Internet é cada vez mais empregada como meio didático, em todos os níveis de ensino", mas, por outro lado, questiona o uso que os educadores estão fazendo desta ferramenta no uso educacional. A rede, sem dúvida alguma, é um excelente meio didático; entretanto, saber onde e como buscar as informações 
ali disponibilizadas se tornou um grande desafio. Navegar na Internet, mesmo usando sites de busca, pode ser um processo complicado, devido à desordem e ao excesso informacional, sem deixar de mencionar o grande número de informações de conteúdo duvidoso disponíveis na grande rede. Além disso, os educadores devem ter consciência de que

Ensinar utilizando a Internet exige uma forte dose de atenção do professor. Diante de tantas possibilidades de busca, a própria navegação se torna mais sedutora do que o necessário trabalho de interpretação. Os alunos tendem a dispersar-se diante de tantas conexões possíveis, de endereços dentro de outros endereços, de imagens e textos que se sucedem ininterruptamente. (MORAN, 1998, p. 127)

Tendo em vista o que se expôs até este ponto, é possível afirmar que a utilização da Webquest pode contribuir para a mudança na forma de ensinar proposta há várias décadas. De acordo com Castro e Tavares (2005, p.2), o emprego desse instrumento no ensino preenche lacunas e fornece material didático auxiliar, utilizando-se das fontes de informação disponíveis na Internet, além de ser um recurso inovador de apoio ao ensino, pois fornece a aquisição do conhecimento através da pesquisa, estimulando a capacidade de raciocínio e também desenvolvendo o uso da imaginação e de outras habilidades.

Trata-se de um método que pode ser utilizado tanto para ensinar como para aprender. Conforme salientam Carvalho e Dornelles (2007, p.2), a "Webquest possibilita uma sintonia do processo educacional com o mundo globalizado atual, viabilizada pelo acesso do aluno a informações recentes e atualizadas [...]". Ou seja, o educando pode ver mais facilmente, por meio do emprego deste recurso, as relações entre o conteúdo aprendido e seu contexto sociocultural. Além disso, a sua elaboração e arquitetura em formato de desafio acabam por despertar a motivação dos alunos enfadados com os métodos tradicionais de ensino.

Moran (2007, p.5) acrescenta que "resolver uma Webquest é um processo de aprendizagem interessante, porque envolve pesquisa e leitura; interação e colaboração e criação de um novo produto a partir do material e idéias obtidas". Os professores precisam incentivar nos alunos o querer saber, estimulando mais a pesquisa e assim ajudando-os a desenvolver um pensamento criativo e competitivo. Através da Internet é possível melhorar a qualidade do ensino, pois o autor salienta que a Webquest propicia a socialização da informação por estar disponível em rede. Assim, a escola atual deve acompanhar as novas tendências informacionais, possibilitando ao educando novas formas de aquisição do conhecimento no processo de aprendizagem capazes de estimular a criação de estratégias que favoreçam o desenvolvimento pleno deste individuo em relação à informação.

A respeito desta conjuntura, vemos em Seabra (1994, p. 2) a importante observação de que "[...] a educação não apenas tem que se adaptar às novas necessidades como, principalmente, tem que assumir um papel de ponta nesse processo". É notório que as novas tecnologias da 
informação encontram-se totalmente inseridas em todos os setores da sociedade e que a escola também precisa se adaptar a essa nova realidade, mas é preciso que haja um preparo para isso. De acordo com Beskow (2006, p. 2), mesmo tendo sido "[...] aprovada em 1996, a Lei $n^{\circ}$ 9394/96, que torna obrigatória a inserção das novas tecnologias nas instituições de ensino [...]", a inclusão digital nas escolas não passa da simples aquisição de computadores. Afirma a referida autora que as instituições educacionais não estão aptas a utilizar recursos tecnológicos nas áreas pedagógicas. Adverte, ainda, que a formação de educadores para as novas tecnologias é urgente e que a escola não pode mais ficar inerte, ela precisa viabilizar o uso da tecnologia.

\section{0 processo metodológico}

Para o desenvolvimento do presente estudo optou-se pela pesquisa-ação, um método de condução de pesquisa baseado na experiência. Thiollent (2000, p. 14) define tal método como sendo...

[...] um tipo de pesquisa com base empírica que é concebida e realizada em estreita associação com uma ação ou com a resolução de um problema coletivo e no qual os pesquisadores e os participantes representativos da situação ou do problema estão envolvidos de modo cooperativo ou participativo

Com fundamentação no conceito do autor citado, vê-se que esse tipo de pesquisa requer a participação das pessoas envolvidas no problema investigado.

A definição do campo desta investigação exigiu, a princípio, uma análise preliminar, já que o alvo era uma escola que contasse com um laboratório de informática com acesso à Internet. A população do estudo se constituiu de dez alunos da $5^{a}$ série do Ensino Fundamental, com idade entre dez e quinze anos. Delimitou-se esse número em função das possibilidades do laboratório da escola pesquisada. O desenvolvimento do projeto de incentivo ao gosto pela leitura usando a metodologia Webquest ocorreu durante os meses de agosto a dezembro do ano letivo de 2007.

Como instrumento para a coleta de informações junto ao professor, utilizou-se a entrevista semi-estruturada. Com os estudantes, além da entrevista, utilizou-se também a observação participante, que ocorreu durante o desenvolvimento do projeto.

Para a aquisição dos resultados, usou-se o software livre PHPWebquest, baseado nos ensinamentos de Dodge (1995). Iniciou-se, então, a elaboração de uma Webquest, "Magia da Leitura"1 com 0 propósito de estimular o gosto pela leitura, procurando analisar as experiências e as opiniões junto aos educandos sujeitos da pesquisa.

\footnotetext{
Webquest está disponível no endereço: $<$ http://livre.escolabr.com/ferramentas/wq/webquest/soporte tablon w.php?id actividad=6089\&id p agina=1 >. Acesso em: 06 mar. 2009.
} 
A coleta de dados por meio da observação participante seguiu um roteiro cuja elaboração visou a identificar possíveis dificuldades dos alunos em relação ao uso da Webquest.

Deve ser destacado o desempenho da bibliotecária que fez parte do grupo de pesquisa. Ela elaborou a Webquest utilizada, aplicou-a junto aos alunos e orientou os mesmos, enquanto bibliotecária na busca e obtenção das informações e na construção de conhecimentos a partir destas novas informações. Este trabalho, que ajudou a despertar nas crianças o gosto pelo recurso didático empregado, pela leitura e pela pesquisa, comprovou a importância de um profissional bibliotecário nas bibliotecas escolares.

\subsection{Descrição e análise dos resultados}

Os resultados obtidos por meio deste estudo indicam que a Webquest não provocou para os alunos momentos de incompreensão, e despertou o interesse dos mesmos pela leitura, sendo muito bem aceita por eles. Assim, é possível afirmar que o objetivo principal foi atingido, confirmando que a leitura deve, sempre que possível, ser realizada de forma prazerosa, proporcionando a quem a realiza uma conquista de novos horizontes e novas aprendizagens, cativando o leitor de forma motivadora para essa atividade.

Para a análise dos resultados seguiram-se basicamente os roteiros de observação participante e os das entrevistas realizadas.

No decorrer do projeto, notou-se que houve mudança na atitude dos alunos quanto a esse novo recurso, uma vez que, embora no começo tivessem achado o mesmo estranho, na entrevista eles foram unânimes em afirmar que o consideraram fácil e que gostaram, a ponto de expressarem o desejo de terem outras aulas com a Webquest. Além disso, notou-se também uma evolução no interesse pela leitura em si e na participação nas aulas, conforme declaração de um docente entrevistado.

Também foi solicitado o parecer da Coordenadora Pedagógica da escola que acompanhou o desenvolvimento da pesquisa. Segundo ela, o projeto de incentivo à leitura através da Webquest no laboratório de informática foi bem aceito por parte dos alunos e conseguiu, efetivamente, despertar seu interesse. Considerou que o projeto foi bem sucedido e que, se for possível, dar continuidade a ele será muito oportuno para a unidade escolar em foco.

\section{Considerações finais}

Através deste trabalho pretendeu-se enfocar a importância do bibliotecário escolar dentro do processo ensino-aprendizagem, buscando estimular $\mathrm{o}$ ato da leitura pelo envolvimento dos alunos em atividades dinâmicas e criativas; pois o caso da leitura, que se reflete no processo de aprendizagem, é um caso a ser levado a sério. Há quem culpe a escola por isso, outros acusam os pais da nova geração que não têm o gosto de ler para os filhos, sem deixar de mencionar o número de bibliotecas escolares desativadas, entre outros fatores. 
É evidente que a leitura é extremamente importante para o crescimento intelectual do ser humano, desde o nascimento até a velhice. Portanto, não importa saber quem é o vilão da história, mas lembrar que depende de nós, pais e educadores (professores e bibliotecários), que se proporcione às crianças o contato com a leitura, promovendo o envolvimento necessário para isso. Desta forma, considera-se que a leitura através da Internet pode ser aproveitada, sim, e que esta constitui uma ferramenta envolvente, motivadora, diversificada, atualizada, questionadora e geradora de opinião.

Nesta perspectiva, é lícito afirmar que durante o desenvolvimento do projeto houve uma conscientização da importância da leitura e uma aprendizagem significativa por parte dos educandos.

Pode-se afirmar que os objetivos estabelecidos foram atingidos, pois as crianças foram, efetivamente, envolvidas nas atividades de leitura. Além disso, elas demonstraram prazer em participar da experiência e, segundo um professor de Português entrevistado, houve uma boa mudança, pois elas começaram a se oferecer para fazer a leitura de textos e mudaram até mesmo no comportamento, participando mais das aulas. Esse mesmo educador declarou que costuma ler para as crianças e que solicita a leitura de textos de vários gêneros; todavia, em relação à Webquest, confessou nunca ter ouvido falar antes sobre isso. No entanto, percebeu efeitos positivos nos discentes que participaram do projeto. Quanto a usar a Internet nas aulas, disse que a utilizava, mas, de acordo com os alunos, isto só acontecia com jogos educativos.

A atividade aplicada também despertou o interesse de outros docentes da unidade escolar. Um fato a ser comprovado, visto que alguns professores procuraram esta pesquisadora para confidenciar o seu interesse não pelo projeto em si, mas pelo simples uso do computador, solicitando ajuda para isso. Esses profissionais foram aconselhados a fazer um curso básico de computação. Ficou nítido o desconforto dos mesmos quanto à sua "desatualização", que acaba por constituir um obstáculo no desempenho de qualquer profissional.

\section{Referências}

ANTUNES, W. A. Bibliotecas escolares: curso de capacitação do professor regente de biblioteca. Brasília: Walda Antunes Consultoria, 1993.

BARROS, G. C. Webquest: metodologia que ultrapassa os limites do ciberespaço. 2005.2 Disponível em: $<$ http://www.gilian.escolabr.com/textos/webquest giliancris.pdf $>$. Acesso em: 12 jun. 2006.

BELMIRO, A. Fala, escritura e navegação: caminho da cognição. In: COSCARELLI, C. V. (Org.) Novas tecnologias, novos textos, novas formas de pensar. Belo Horizonte: Autêntica, 2006. 
BESKOW, C. Á. Inclusão digital na escola pública: inter-relacionando a comunicação, a tecnologia e a educação. 2006. Disponível em: $<$ http://www.cibersociedad.net/congres2006/gts/comunicacio.php?id=840 \&llengua $=$ en $>$. Acesso em: 10 fev. 2007.

BLATTMANN, U.; CIPRIANO, A. S. Os diferentes públicos e espaços da biblioteca escolar: da pré-escola à universidade. Florianópolis, 1998. Disponível em: <http://www.geocities.com/ublattmann/papers/p12.html>. Acesso em: 15 mar. 2003.

CARVALHO, A. S.; DORNELLES, L. M. A. O uso da Webquest como ferramenta educacional no projeto alfabetização em GIS/SIG - ensino médio. RJ, $2007 . \quad$ Disponível em: $<$ http://aveb.univap.br/opencms/opencms/sites/ve2007neo/pt-

BR/imagens/27-06-

07/Escola/trabalho 74 carlax20ex20ucineide anais.pdf $>$. Acesso em: 22 out. 2007.

CASTRO, J. I.; TAVARES, J. M. R. S. Webquest: um instrumento didático inovador. $2005 . \quad$ Disponível em: $<$ http://www.fe.up.pt/si/file get.publ artigo?p id=6334>. Acesso em: 3 dez. 2006.

CORRÊA, E. C. D. et al. Bibliotecário escolar: um educador? Revista $A C B$ : Biblioteconomia em Santa Catarina, v. 7, n. 1, p. 107-123, 2002.

CORRÊA, J. Novas tecnologias da informação: novas estratégias de ensino/aprendizagem. In: COSCARELLI, C. V. (org.) Novas tecnologias, novos textos, novas formas de pensar. Belo Horizonte: Autêntica, 2006.

COSTA, A. L.; HILLESHEIM, A. I. A. Atividades de incentivo a leitura na escola básica Padre João Alfredo Rohr. 2004. Disponível em: $<$ http://www.extensio.ufsc.br/20041/artigos pdfs/CED Araci.pdf> Acesso em: 24 mar. 2007.

COSTA, W. A. 50 sugestões didático-pedagógicas para o ensino da leitura e da escrita em sala de aula. Cuiabá: EdUFMT, 2006.

DODGE, B. Webquest: uma técnica para a aprendizagem na rede internet. $1995 . \quad$ Disponível em: $<$ http://www.webquest.futuro.usp.br/artigos/textos bernie.html $>$. Acesso em: 20 dez. 2006.

FRAGOSO, G. M.; DUARTE, R. Livro, leitura, biblioteca... Uma história sem fim. Revista ACB: Biblioteconomia em Santa Catarina, Florianópolis, v. 9, n.1 p. 166-170, 2004.2 Disponível em: <http://www.acbsc.org.br/revista/ojs/viewarticle.php?id=81\&layout=html $>$ Acesso em: 02 set. 2006 
HILLEBRAND, R. C. Pesquisa escolar, uma motivação ao ensino de qualidade. Revista Educare, p. 65-72, v. 4, n.1, jan./jun. 2004. Disponível em: <http://revistas.unipar.br/educere/article/view/180/154>. Acesso em: 30 mar. 2006.

HILLESHEIM, A. I. A; FACHIN, G. R. B. Biblioteca escolar e a leitura. Rev. $A C B$, Florianópolis, v.8, n.1, p. 35-45, 2003.

INTERNATIONAL FEDERATION OF LIBRARY ASSOCIATIONS - IFLA. ORGANIZAÇÃO DAS NAÇÕES UNIDAS - UNESCO. Manifesto para Biblioteca Escolar. São Paulo, 2000. Disponível em: <http://www.ifla.org/VII/s11/pubs/portuguese-brazil.pdf> Acesso em: fev. 2008.

KUHLTHAU, C. Como usar a biblioteca na escola: um programa de atividades para o ensino fundamental. Belo Horizonte: Autêntica, 2002.

O papel da biblioteca escolar no processo de aprendizagem. Belo Horizonte, 1999.

Disponível

em: $<$ http://www.eci.ufmg.br/gebe/downloads/103.pdf>. Acesso em: 18 jan. 2005.

LÉVY, P., 1999 apud BELMIRO, A. Fala, escritura e navegação: caminho da cognição. In: COSCARELLI, C. V. (Org.) Novas tecnologias, novos textos, novas formas de pensar. Belo Horizonte: Autêntica, 2006.

MARQUES NETO, H. T. A tecnologia da informação na escola. In: COSCARELLI, C. V. (Org.) Novas tecnologias, novos textos, novas formas de pensar. Belo Horizonte: Autêntica, 2006.

MARTUCCI, E. M. Rompendo o silêncio: a biblioteca escolar e a trajetória de um pesquisador. Belo Horizonte, 1999. Disponível em: $<$ http://www.eci.ufmg.br/gebe/downloads/105.pdf $>$. Acesso em: 10 jan.2003.

MININI, R. Ensinar aos jovens o prazer da leitura é objetivo em todo o mundo. Revistaparadoxo.com. Correspondente em Londres, 2004. Disponível

em: $<$ http://www.revistaparadoxo.com/materia.php?ido=1645>. Acesso em: 11 maio. 2007.

MORAN, J. M. Como utilizar a internet na educação. Ciência da Informação, v. 26, n. 2, p. 146 - 153, ago. 1997. Disponível em: $<$ http://www.eca.usp.br/prof/moran/internet.htm>. Acesso em: 22 abr. 2007.

. Internet no ensino universitário: pesquisa e comunicação na sala de aula. Interface: Comunicação, Saúde, Educação, v. 2, n. 3, p. 125-32, ago. $1998 . \quad$ Disponível em: $<$ http://www.interface.org.br/revista3/debates3.pdf> Acesso em: 10 set. 2006 
. Como utilizar as tecnologias na escola. 2007. Disponível em: <http://www.eca.usp.br/prof/moran/utilizar.htm>. Acesso em: $02 \mathrm{dez}$. 2007.

MORO, E. L. S.; SABBADINI, F.; ESTABEL, L. B. A integração dos atores alunos, educadores e bibliotecários - na realização da pesquisa escolar através da utilização das tecnologias de informação e de comunicação. 2002. Disponível

em: <http://www.eci.ufmg.br/gebe/downloads/304.pdf>. Acesso em: 19 mai. 2007.

RHATTO, S. Manual prático de html. 2006. Disponível em: <http://docs.indymedia.org/view/Sysadmin/GuiaHtml\#HTML_B_sico>.

Acesso em: 02 jan. 2008.

SANTOS, G. L. A internet na escola fundamental: sondagem de modos de uso por professores. Educação e Pesquisa, v. 29, n. 2, São Paulo, jul./dec. 2003. Disponível em:

$<$ http://www.scielo.br/scielo.php?script=sci arttext\&pid=S1517-

97022003000200008 >. Acesso em: 10 set. 2006.

SEABRA, C. Novo método orienta pesquisa na Internet. 2001. Revista EducaRede. em: $<$ http://www.educarede.org.br/educa/img conteudo/tecnologia4.html >. Acesso em: 24 dez. 2006.

- Uma nova educação para uma nova era. São Paulo, 1994. Disponível em: <http://www.cidec.futuro.usp.br/artigos/artigo11.html>. Acesso em: 19 nov. 2006.

SENAC. $O$ que é. 2003. Disponível em: <http://webquest.sp.senac.br/textos/oque>. Acesso em: 21 ago. 2006.

SILVA, W. C. Miséria da biblioteca escolar. São Paulo: Cortez, 1995.

THIOLLENT, M. Metodologia da pesquisa-ação. 9. ed. São Paulo: Cortez, 2000.

VALENTE, J. A. Informática na educação: o computador auxiliando o processo de mudança na escola. Campinas-SP, [200-?]. Disponível em: <http://www.nte-jgs.rct-sc.br/valente.htm>. Acesso em: 11 out. 2006.

ZILBERMAN, R. Leitura: história e sociedade. São Paulo: FDE, 1988. (Série Idéias n.5). Disponível em: $<$ http://www.crmariocovas.sp.gov.br/lei_a.php?t=003>. Acesso em: 27 set. 2003. 